Artikel Penelitian

\title{
Distribusi Spasial Logam Berat Besi (Fe) di Perairan Teluk Staring, Sulawesi Tenggara
}

\author{
Bahril $^{1}$, Armid $^{1 *}$, Jabir ${ }^{1}$, Amadhan Takwir², Abdul Rahim ${ }^{3}$ \\ 1 Jurusan Kimia, Fakultas Matematika dan IImu Pengetahuan Alam, Universitas Halu Oleo, Kendari, Indonesia, 93232 \\ 2Jurusan IImu Kelautan, Fakultas Perikanan dan IImu Kelautan, Universitas Halu Oleo, Kendari, Indonesia, 93232 \\ 3Jurusan Manajemen Sumberdaya Perairan, Fakultas Perikanan dan IImu Kelautan, Universitas Halu Oleo, Kendari, Indonesia
} 93232

INFO ARTIKEL

\section{Riwayat Artikel}

Diterima 18 Juni 2019

Direvisi 13 September 2019

Tersedia online 4 Desember 2019

* Email penulis korespondensi: alrum.armid@gmail.com

\section{ABSTRAK}

Study on spatial distribution of metal Fe in the coastal area of Staring Bay, Southeast Sulawesi has been carried out. This study aims to determine the spatial distributions of heavy $\mathrm{Fe}$ in the coastal area of Staring Bay. Sampling was conducted at 12 stations along the bay through the purposive sampling method. Determination of heavy metal Fe concentration was performed utilizing the Atomic Absorption Spectrophotometry (AAS). Spatial analysis was performed with IDW interpolation method using a software ArcGIS 10.3. The results showed that the concentration of metal Fe at 12 stations was in the range of $0.00187 \mathrm{ppm}$ to 0.01296 ppm whereby the highest level was found at station 7 (mouth of the Laonti river). The spatial analysis in 12 stations confirmed that in the coastal areas of Woru-woru village (near the mouth of the Laonti river) to Gala Island and Wandahea village up to Intan Island have been contaminated by metal Fe ranged from $0.0106-0.0117$ ppm and 0.0118-0.013 ppm, respectively. The contamination factor of metal Fe was moderate. Based on the values of CF, the highest contamination of heavy metal Fe is at station 7 .

Keywords: Spatial analysis, Fe, IDW, CF, Staring Bay

Telah dilakukan studi distribusi spasial logam Fe di perairan Teluk Staring, Sulawesi Tenggara. Penelitian ini bertujuan untuk menentukan sebaran spasial logam Fe di perairan Teluk Staring. Pengambilan sampel dilakukan 12 stasiun di perairan teluk dengan metode purposive sampling. Penentuan kadar logam Fe pada sampel air laut menggunakan Atomic Absorption Spectrophotometry (AAS). Analisis spasial dilakukan dengan metode interpolasi IDW menggunakan software ArcGIS 10.3. Hasil penelitian menunjukkan bahwa kadar logam Fe di 12 stasiun penelitian berkisar antara 0,00187-0,01296 ppm dengan kadar tertinggi berada pada stasiun 7 (muara Sungai Laonti). Hasil analisis spasial pada 12 stasiun menunjukkan bahwa di daerah pesisir Desa Woru-woru (dekat muara Sungai Laonti) hingga Pulau Gala dan Desa Wandahea hingga Pulau Intan telah terkontaminasi logam Fe dengan kisaran 0,0106-0,0117 ppm dan 0,0118-0,013 ppm. Faktor kontaminasi logam Fe bersifat moderat. Berdasarkan nilai CF, kontaminasi tertinggi oleh logam $\mathrm{Fe}$ terdapat pada stasiun 7 .

Kata kunci: Analisis spasial, Fe, IDW, CF, Teluk Staring 


\section{Pendahuluan}

Teluk Staring merupakan suatu perairan laut yang termasuk ke dalam wilayah administrasi Kecamatan Laonti, Kecamatan Moramo dan Kecamatan Moramo Utara Kabupaten Konawe Selatan, Sulawesi Tenggara [1]. Secara geografis Teluk Staring terletak di antara 402'40"-4'08'53"LS dan 122040'03"-122048'02"BT. Teluk ini memiliki potensi sumber daya alam hayati dan non hayati sehingga banyak dimanfaatkan oleh masyarakat setempat untuk melakukan berbagai aktivitas yang meliputi kegiatan budidaya rumput laut [2], perikanan tangkap dan pertambakan udang/ikan [3].

Padatnya aktivitas industri dan domestik menjadi faktor utama pencemaran limbah yang dibuang dan bermuara ke perairan teluk. Keadaanya diperparah dengan adanya aliran sungai yang bermuara di teluk dimana pada musim hujan membawa padatan tersuspensi yang menyebabkan perairan menjadi keruh [1]. Pencemar utama yang terkandung dalam buangan limbah adalah logam berat yang beracun [4].

Wijayanti [5] menyatakan bantaran sungai pada suatu daerah aliran sungai mempunyai konsentrasi logam berat yang sangat tinggi. Oleh karena itu, analisis unsur-unsur logam pencemar di perairan laut sebagai muara dari aliran sungai perlu dilakukan untuk mengetahui apakah telah terjadi pencemaran oleh logam-logam berbahaya atau sebagai data awal untuk mengetahui tingkat pencemaran [6]. Apabila kadar besi dalam sampel melebihi ambang batas yang telah ditentukan oleh dinas kesehatan (0,3 mg/L), maka air tersebut dinyatakan telah tercemar [7].

Banyak penelitian telah dilakukan di wilayah perairan Teluk Staring. Namun, penelitian tentang kadar logam berat masih sangat terbatas dan perlu dicatat bahwa analisis data pemantauan yang banyak dilakukan hanya berdasarkan data per stasiun sehingga hanya diketahui kondisi pada stasiun tersebut. Akan tetapi, sebaran representatif suatu material pencemar masih belum diketahui sehingga diperlukan suatu metode analisis yang dapat menunjukkan distribusi logam secara spasial sehingga data yang dihasilkan akan mewakili keseluruhan perairan teluk. Salah satu alternatif yang diberikan yaitu analisis spasial dengan metode interpolasi Inverse Distance Weight.

Dalam studi ini, metode interpolasi diterapkan pada analisis spasial logam Fe di perairan Teluk Staring. Penetapan logam Fe disebabkan karena logam Fe merupakan unsur yang dapat ditemui pada hampir setiap tempat di bumi, pada semua lapisan geologis dan semua badan air, bioakumulatif, sering dijumpai telah melewati standar baku mutu logam Fe untuk wilayah perairan teluk $[8,9,10]$. Studi analisis spasial dan faktor kontaminasi logam Fe dalam sistem perairan Teluk Staring sangat penting untuk dilakukan mengingat banyak sumber input yang berpotensi menimbulkan pencemaran logam Fe. Dengan demikian hasil penelitian ini dapat menjadi rujukan bagi pengambil kebijakan di tingkat daerah Provinsi Sulawesi Tenggara mengenai keberadaan logam Fe secara spasial di perairan Teluk Staring.

\section{Bahan dan Metode}

\subsection{Bahan}

Bahan yang digunakan dalam penelitian ini adalah asam klorida $(\mathrm{HCl})$ p. a. (Merck), asam nitrat $\left(\mathrm{HNO}_{3}\right) 70 \%$, larutan standar Fe 1000 ppm dan akuades.

\subsection{Sampel dan Desain Eksperimen}

Sampling dilakukan pada 12 stasiun (Gambar 1) yaitu stasiun 1 (kawasan perairan PLTU), stasiun 2 (kawasan perairan tambang batu moramo), stasiun 3 (kawasan perairan payau), stasiun 4 (kawasan perairan pabrik semen), stasiun 5 dan 6 (kawasan perairan teluk bagian dalam), stasiun 7 (kawasan muara Sungai Laonti), stasiun 8 dan 9 (kawasan perairan teluk bagian dalam), stasiun 10,11 dan 12 (kawasan mulut teluk). Tabel 1 memperlihatkan keadaan parameter $\mathrm{pH}$, salinitas dan suhu di setiap stasiun pada saat sampling.

\subsection{Pengambilan Sampel Air Laut}

Sampel air laut diambil langsung pada setiap titik koordinat yang telah ditentukan dengan GPS. Setelah itu, dilakukan penambahan $\mathrm{HCl}$ pekat sebanyak 1 tetes sebagai pengkondisi untuk mencegah logam agar tidak menempel pada dinding wadah. Kemudian sampel disimpan dalam cooler box. Sampel air laut yang telah diambil dari perairan Teluk Staring, selanjutnya dibawa ke Laboratorium IImu Tanah Fakultas Pertanian, Universitas Halu Oleo, Kendari untuk dipreparasi dan dianalisis lebih lanjut.

\subsection{Preparasi Sampel Air Laut}

Sampel air laut kemudian difilter dengan filter Millipore HA (ukuran pori 0,45 $\mu \mathrm{m}$ ) untuk menghilangkan materi organik dalam sampel. Kemudian, masing-masing sampel dipipet sebanyak $5 \mathrm{~mL}$ ke dalam labu takar $10 \mathrm{~mL}$. Selanjutnya, ditepatkan dengan larutan $\mathrm{HNO}_{3} 1 \%$ sampai garis batas labu takar dan dihomogenkan dan sampel air laut siap untuk dianalisis [11]. 


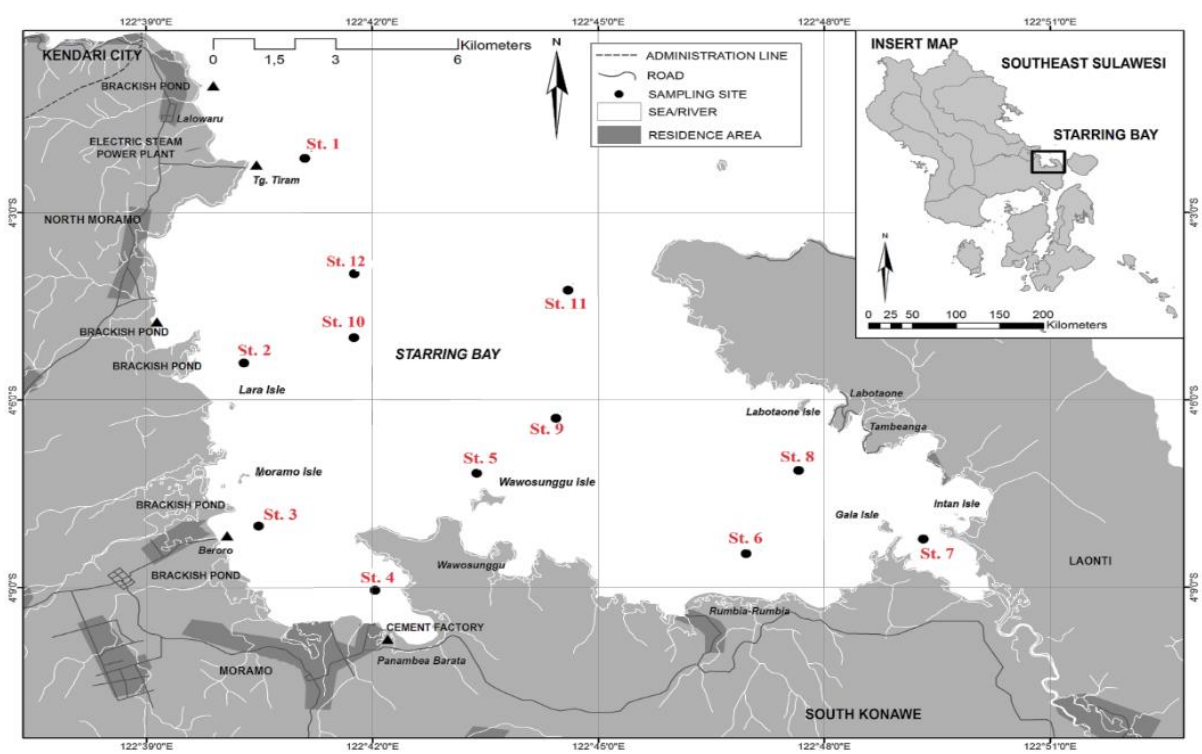

Gambar 1. Kawasan perairan Teluk Staring memperlihatkan 12 stasiun sampling.

Tabel 1. pH, Salinitas dan Suhu Air Tiap Stasiun

\begin{tabular}{cccccc}
\hline \multirow{2}{*}{ Stasiun } & \multicolumn{2}{c}{ Koordinat } & \multirow{2}{*}{ pH } & \multirow{2}{*}{ Salinitas $(\%)$} & \multirow{2}{*}{ Suhu $\left({ }^{\circ} \mathrm{C}\right)$} \\
\cline { 2 - 5 } & BT & LS & & & 28,5 \\
$\# 1$ & $122^{\circ} 41^{\prime} 6.44^{\prime \prime}$ & $4^{\circ} 2^{\prime} 7.79^{\prime \prime}$ & 7,95 & 34,9 & 28,5 \\
$\# 2$ & $122^{\circ} 40^{\prime} 17.68^{\prime \prime}$ & $4^{\circ} 5^{\prime} 24.39^{\prime \prime}$ & 7,91 & 34,63 & 28,9 \\
$\# 3$ & $122^{\circ} 40^{\prime} 29.26^{\prime \prime}$ & $4^{\circ} 8^{\prime} 0.95^{\prime \prime}$ & 7,92 & 34,32 & 30 \\
$\# 4$ & $122^{\circ} 42^{\prime} 2.19^{\prime \prime}$ & $4^{\circ} 9^{\prime} 2.77^{\prime \prime}$ & 8,07 & 30,43 & 29,9 \\
$\# 5$ & $122^{\circ} 43^{\prime} 23.20^{\prime \prime}$ & $4^{\circ} 7^{\prime} 10.34^{\prime \prime}$ & 7,9 & 33,7 & 28,6 \\
$\# 6$ & $122^{\circ} 46^{\prime} 57.83^{\prime \prime}$ & $4^{\circ} 8^{\prime} 27.56^{\prime \prime}$ & 7,51 & 34,9 & 28,6 \\
$\#$ & $122^{\circ} 49^{\prime} 18.90^{\prime \prime}$ & $4^{\circ} 8^{\prime} 13.66^{\prime \prime}$ & 7,71 & 24,83 & 27,9 \\
$\# 8$ & $122^{\circ} 47^{\prime} 39.56^{\prime \prime}$ & $4^{\circ} 7^{\prime} 7.75^{\prime \prime}$ & 7,94 & 34,12 & 28,2 \\
$\# 9$ & $122^{\circ} 44^{\prime} 26.20^{\prime \prime}$ & $4^{\circ} 6^{\prime} 17.44^{\prime \prime}$ & 7,52 & 36,11 & 28,6 \\
$\# 10$ & $122^{\circ} 41^{\prime} 45.48^{\prime \prime}$ & $4^{\circ} 5^{\prime} 0.16^{\prime \prime}$ & 7,92 & 36,32 & 28 \\
$\# 11$ & $122^{\circ} 44^{\prime} 35.97^{\prime \prime}$ & $4^{\circ} 4^{\prime} 14.46^{\prime \prime}$ & 7,7 & 35,87 & 28,4 \\
$\# 12$ & $122^{\circ} 41^{\prime} 45.70^{\prime \prime}$ & $4^{\circ} 3^{\prime} 58.80^{\prime \prime}$ & 8,2 & 36,24 & 28 \\
\hline
\end{tabular}

\subsection{Analisis Laboratorium}

\subsubsection{Deret Larutan Standar Fe}

Larutan standar Fe 10 ppm dibuat dari larutan Fe 1000 ppm yang telah disiapkan. Selanjutnya, larutan $\mathrm{Fe} 10 \mathrm{ppm}$ dipipet sebanyak 25, 50, 75, 100 dan $150 \mu \mathrm{L}$ masing-masing ke dalam labu takar $100 \mathrm{~mL}$. Setelah itu, ditepatkan dengan larutan $\mathrm{HNO}_{3} 1 \%$ sampai tanda batas labu takar sehingga diperoleh konsentrasi logam Fe 0,0025; 0,0050;0,0075; 0,010 dan $0,015 \mathrm{ppm}$.

\subsubsection{Penentuan Kadar Logam Fe}

Kadar Fe pada sampel ditentukan dengan metode kurva kalibrasi standar menggunakan Atomic Absorption Spectrophotometer (AAS) (Hitachi Z-2000) pada panjang gelombang 248,3 nm.

\subsection{Analisis Spasial Distribusi Fe}

Peta dasar (base map) penelitian yang diperoleh dari hasil scan kemudian di-digitasi. Sebelum di-digitasi terlebih dahulu dilakukan proses registrasi peta agar base map penelitian memiliki titik koordinat melalui proses georeferensing pada software pengolah data (ArcGIS 10.3) yang digunakan. Selanjutnya dilakukan proses digitasi. Proses digitasi diawali dengan pembuatan layer yang nantinya disimpan (format shapefile) yang meliputi digitasi daerah daratan dan lautan, stasiun sampling, sungai serta nama-nama daerah di sekitar teluk.

Proses selanjutnya yaitu input. Pada proses ini, semua layer dari hasil digitasi kemudian diinput ke ArcGIS 10.3 . Semua layer data diberikan label agar memudahkan analisis spasialnya. Selanjutnya, dilakukan interpolasi data dengan 
metode IDW dengan power 2. Setelah peta hasil interpolasi berhasil dilakukan proses layout dan penyimpanan peta. Persamaan metode IDW telah terintegrasi pada software pemetaan yang digunakan sehingga memudahkan proses interpolasi.

\subsection{Analisis Faktor Kontaminasi (Contamination Factor atau CF)}

Hasil pengukuran konsentrasi sampel air laut di 12 stasiun sampling di perairan Teluk Staring dibandingkan dengan kadar base line logam Fe untuk perairan alami dan base line logam Fe untuk perairan di Indonesia sehingga diperoleh nilai CF logam Fe di 12 stasiun. Penentuan CF dapat menggunakan Persamaan (1).

$$
\mathrm{CF}=\frac{\mathrm{C}_{\mathrm{x}}}{\mathrm{C}_{\text {Background }}\left(\mathrm{B}_{\mathrm{n}}\right)}
$$

dimana $\mathrm{C}_{\mathrm{x}}$ adalah kadar logam pada tiap lokasi sampling dan $\mathrm{C}_{\text {Background }}\left(\mathrm{B}_{\mathrm{n}}\right)$ adalah kadar normal (base line) logam di alam. Kriteria berikut digunakan untuk menggambarkan tingkat kontaminasi: $\mathrm{CF}<1$ (rendah), $1 \leq \mathrm{CF}<3$ (sedang) dan $3 \leq \mathrm{CF}<6$ (tinggi), CF $>6$ (sangat tinggi) [12].

\section{Hasil dan Pembahasan}

\subsection{Kadar Fe dalam Sampel Air Laut}

Penggunaan AAS dikarenakan intrumen ini mampu menganalisis berbagai macam logam dengan tingkat kepekaan yang tinggi. Dalam pelaksanaannya, pengukuran dengan AAS harus dalam suasana $\mathrm{pH}$ rendah. Pada $\mathrm{pH}$ rendah proses atomisasi akan berjalan dengan optimal [13]. Oleh karena itu, perlu dilakukan pengasaman terlebih dahulu terhadap larutan baik pada larutan sampel air laut maupun pada larutan standar yang digunakan.

Pada penelitian ini pengasaman dilakukan pada $\mathrm{pH}$ dengan penambahan $\mathrm{HNO}_{3} . \mathrm{HNO}_{3}$ dipilih karena larutan ini merupakan asam kuat yang berfungsi sebagai zat oksidator yang membantu penghilangan zat organik dari materi biologis sehingga yang tersisa hanya zat anorganiknya. Kondisi asam pada sampel akan membuat unsur-unsur logam berat akan mudah melarut sehingga pembacaan saat pengukuran dapat berjalan dengan baik.

Salah satu metode yang digunakan dalam penentuan konsentrasi suatu unsur dalam analit yaitu metode kurva kalibrasi standar. Dalam metode kurva kalibrasi standar, analisis menggunakan AAS dibutuhkan beberapa larutan standar yang dibuat dari bentuk ion atau garam dari logam yang dianalisis yang sudah diketahui konsentrasinya secara pasti. Pada penelitian ini dibuat deret larutan standar dengan range tertentu yang disesuaikan dengan base line logam berat yang diteliti. Kurva kalibrasi standar logam Fe terlihat pada Gambar 2.

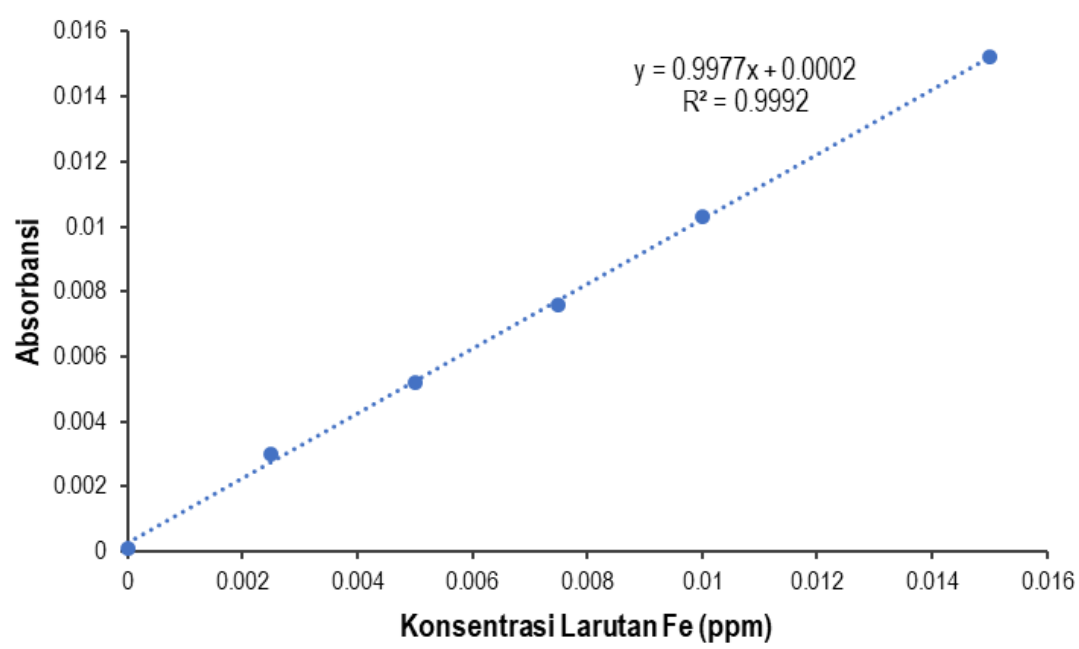

Gambar 2. Kurva kalibrasi larutan standar Fe.

Pada Gambar 2 terlihat bahwa nilai koefisien korelasi yaitu 0,9992. Nilai $R$ tersebut dapat diterima karena $>0,9990$ [14]. Nilai $R$ positif menunjukkan korelasi yang berbanding lurus antara konsentrasi terhadap absorbansnya pada rentang konsentrasi larutan standar tersebut. Nilai R dikatakan baik apabila mendekati 1 [15]. Nilai R yang diperoleh pada penelitian ini berada pada rentang nilai antara $-1 \leq R \leq 1$ dan mendekati 1 sehingga dapat dikatakan linearitas data yang diperoleh antara konsentrasi dan absorbans sangat baik dan metode tersebut dapat digunakan untuk analisis logam Fe. 
Secara alami, eksistensi logam berat pada perairan laut telah terdeteksi walaupun dalam level yang sangat rendah, dalam hal ini Fe memiliki base line sebesar 0,0034 ppm [16]. Berdasarkan hasil analisis yang dilakukan, konsentrasi logam Fe pada 12 stasiun pengamatan terlihat adanya perbedaan yang signifikan antarstasiun maupun antara stasiun dengan base line yang telah ditetapkan (Gambar 3 ).

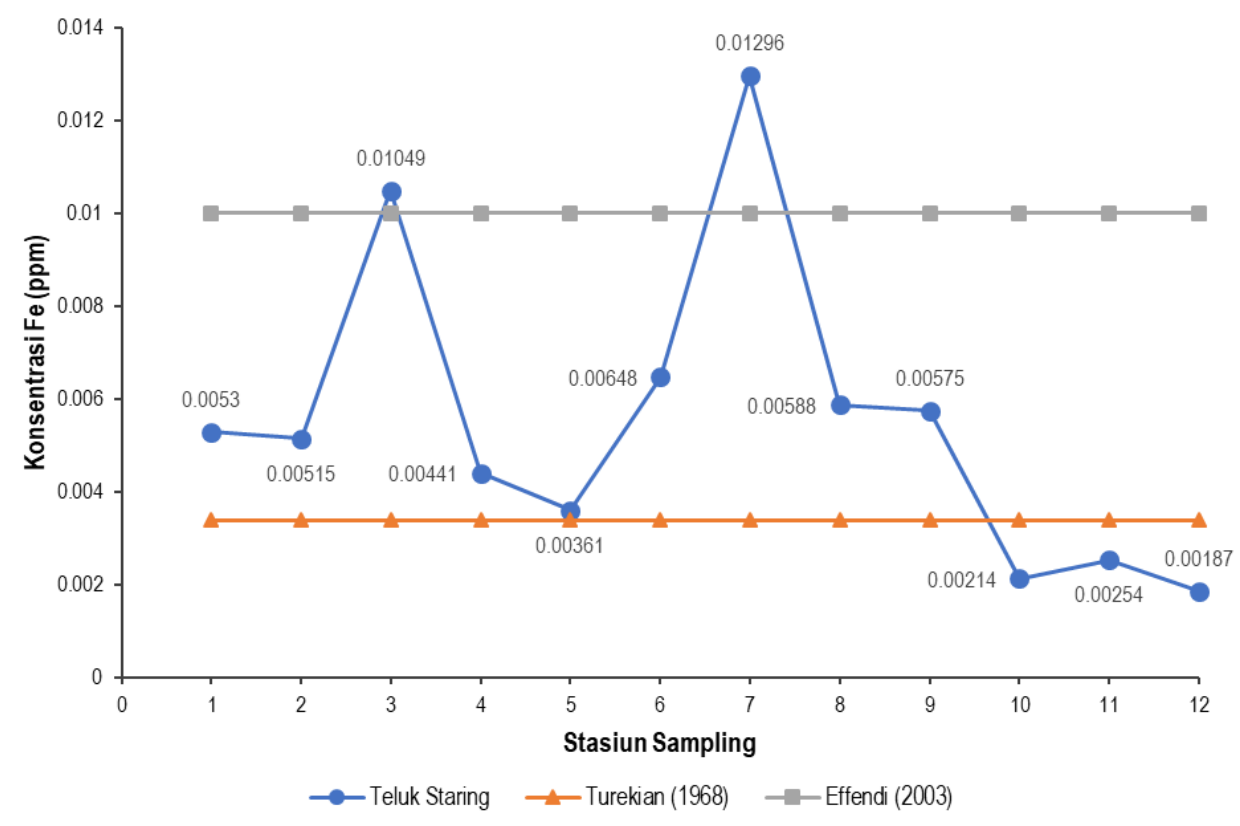

Gambar 3. Kadar logam Fe di Teluk Staring, base line di perairan alami dan Indonesia.

Berdasarkan Gambar 3, terlihat bahwa konsentrasi sampel air laut di 12 stasiun berkisar antara 0,00187-0,01296 ppm (rerata 0,0056 ppm) telah melebihi standar baku mutu yang ditetapkan untuk logam Fe di perairan alami yakni 0,0034 ppm [16]. Akan tetapi, Effendi [17] menyatakan nilai rerata tersebut masih berada di bawah base line logam Fe yang dapat ditoleransi di perairan Indonesia yaitu 0,01 ppm.

Konsentrasi logam Fe pada stasiun 7 berada jauh di atas base line logam Fe perairan alami dan perairan Indonesia. Tingginya konsentrasi logam Fe pada stasiun 7 diduga berasal dari mineral-mineral tanah di bantaran sungai, limbah domestik dan adanya kegiatan-kegiatan perkapalan di sekitar muara Sungai Laonti. Hal ini sesuai dengan pernyataan Wijayanti [5] yang menyatakan bahwa bantaran sungai pada suatu daerah aliran sungai mempunyai konsentrasi logam berat yang sangat tinggi.

Berdasarkan Gambar 3, terlihat stasiun yang berada di dekat muara Sungai Laonti (St. 7) memiliki tingkat pencemaran yang tinggi seperti pada stasiun 6, 8 dan 9. Hal ini mengindikasikan bahwa distribusi logam Fe di Teluk Staring dimana sungai sebagai sumber input utamanya sudah mulai terdistribusi yang diduga dibawa oleh arus laut. Komarawidjaja [18] menyatakan bahwa kandungan logam berat di daerah tertentu dipengaruhi oleh jaraknya dengan sumber pencemar. Muara menjadi tempat pengendapan limbah sehingga daerah muara merupakan daerah yang menerima tekanan paling besar terhadap dampak dari limbah buangan tersebut [19].

Rahman dan Mansyur [1] menyatakan bahwa stasiun 3 merupakan muara dari kurang lebih delapan sungai sehingga pada stasiun 3 konsentrasi logam Fe juga terlihat tinggi. Walaupun demikian, berdasarkan data salinitas saat sampling, salinitas stasiun 3 lebih tinggi dibanding pada stasiun 7 . Hal ini menjadikan logam berat akan sukar terurai dalam bentuk partikel atau padatan tersuspensinya [20] sehingga hal tersebut diduga sebagai salah satu penyebab konsentrasi logam Fe di stasiun 3 saat sampling tidak lebih besar dari stasiun 7 .

Konsentrasi logam Fe di 12 stasiun pengamatan mengalami fluktuasi. Nilai terendah terdapat pada 3 stasiun terakhir yakni stasiun 10, 11 dan 12. Konsentrasi logam Fe pada 3 stasiun tersebut berada di bawah base line logam Fe di badan air. Hal ini disebabkan karena letak ke 3 stasiun tersebut berada di bagian mulut teluk dan berada jauh dari sumber pencemar. Hal ini juga didukung dengan data variabel lingkungan hasil pengukuran yang dilakukan saat sampling. Hasil analisis memperlihatkan variabel lingkungan yang memberikan dampak besar terhadap kelarutan logam Fe adalah salinitas. Salinitas ke 3 stasiun terakhir tersebut memiliki nilai yang tinggi dan jauh di atas standar baku mutu yang ditetapkan. 
Berdasarkan hasil analisis diketahui bahwa konsentrasi logam Fe di muara sungai memiliki konsentrasi tertinggi. Sumber air yang masuk ke sungai yang kemudian terbawa ke muara sungai menurut Hutagalung [21] yaitu $68 \%$ berasal dari run off air hujan dan sisanya berasal dari air tanah di wilayah sekitar daerah aliran sungai (bantaran sungai). Batara dkk. [22] menambahkan bahwa air tanah mengalami kontak dengan berbagai macam material yang terdapat di dalam bumi sehingga pada umumnya air tanah mengandung kation dan anion terlarut dan beberapa senyawa anorganik dimana salah satunya adalah besi.

Selain itu, logam Fe di perairan Teluk Staring dapat berasal dari aktivitas industri seperti PLTU (St. 1), tambang batu moramo (St. 2) dan pabrik semen (St. 4). Kamarati dkk. [23] menyatakan bahwa dalam buangan limbah industri kandungan besi dapat berasal dari korosi pipa-pipa air mineral logam sebagai hasil elektrokimia yang terjadi pada perubahan air yang mengandung padatan larut mempunyai sifat menghantarkan listrik dan ini mempercepat terjadinya korosi sehingga memicu meningkatnya konsentrasi logam Fe di perairan teluk. Hasyim [24] menyatakan bahwa perkembangan berbagai industri juga dapat meningkatkan jumlah konsumsi pelumas, sehingga menimbulkan banyaknya limbah pelumas bekas. Kasman dkk. [25] menambahkan limbah atau residu oli bekas mengandung sisa hasil pembakaran yang bersifat asam, korosif dan mengandung logam berat yang bersifat karsinogenik.

Aktivitas pertambangan batu moramo (St. 2) yang menggunakan alat berat dapat menghasilkan limbah oli bekas. Hal yang sama juga dinyatakan oleh Dahlan dkk. [26] yang menyatakan bahwa aktivitas tambang batubara di Kabupaten Kutai Kartanegara yang menggunakan alat berat dalam kegiatan operasionalnya menghasilkan limbah oli bekas. Widiyanto [27] menyatakan bahwa kandungan logam Fe oli bekas dua kali lebih besar (3,3 ppm) dibandingkan oli baru (1,73 ppm).

Logam Fe dilaporkan sering dijumpai telah mencemari di berbagai perairan teluk di Dunia. Hasan dkk. [8] melaporkan konsentrasi logam Fe di perairan Teluk Bengal di bagian selatan Bangladesh berada pada kondisi tercemar dengan konsentrasi yang lebih tinggi dibandingkan dengan logam berat lainnya dengan kisaran antara 0,1561-60,454 ppm. Pada tahun yang sama Srichandan dkk. [9] melaporkan konsentrasi logam Fe di perairan Teluk Bengal, India di tahun yang berbeda memiliki kisaran logam Fe yang meningkat yaitu 4,47 ppb (April 2010) menjadi 13,71 ppb (November 2011). Zhang dkk. [10] melaporkan bahwa konsentrasi logam Fe di perairan Teluk Zhanjiang, Cina telah berada pada kondisi tercemar dengan kisaran 60,28-96,96 $\mu \mathrm{g} / \mathrm{L}$.

\subsection{Analisis Spasial Fe}

Keseluruhan proses pemodelan Sistim Informasi Geografis (GIS) dimulai dengan registrasi peta dasar, digitasi peta, input, edit atribut data, interpolasi hingga layout dan penyimpanan data dilakukan dengan menggunakan software ArcGIS 10.3 yang dikeluarkan oleh Environmental Systems Research Institute [28].

Metode interpolasi IDW dilakukan untuk menampilkan kontur Teluk Staring. Armid [28] menyatakan sebaran suatu material cenderung merata untuk daerah dengan kontur yang sejajar disebabkan berada pada posisi ketinggian yang sama. Armid [28] juga menambahkan untuk lingkungan perairan, beberapa titik yang berada pada garis kontur yang sama cenderung mengalami aliran arus yang sama sehingga distribusi material organik maupun anorganik yang tersebar diatasnya tidak akan jauh berbeda disetiap titik. Oleh sebab itu, pola sebaran logam Fe yang telah diinterpolasi dengan metode IDW tidak memiliki perbedaan yang signifikan untuk tiap titik yang berada pada garis kontur yang searah (Gambar 4).

Terdapat dua parameter yang bisa dipelajari dalam interpolasi IDW yaitu power dan jumlah sampel [28]. Parameter power dapat digunakan untuk menentukan pentingnya nilai sampel data pada perhitungan interpolasi. Saffari dkk. [29] dalam Purnomo [30] menyatakan nilai parameter power yang umum digunakan adalah 1, 2, 3, 4 dan 5. Power yang lebih tinggi akan menjadikan kurangnya pengaruh dari sampel data sekitarnya dan hasil interpolasi menjadi lebih detail. Namun, interpolasi sebaran logam Fe pada penelitian ini tidak menitikberatkan pada variasi power IDW melainkan dilakukan pada satu nilai power (power $=2$ ).

Analisis spasial (Gambar 4) dengan metode interpolasi IDW dengan power 2 memperlihatkan besarnya pengaruh dari konsentrasi stasiun sampel terhadap stasiun sampel didekatnya. Hal tersebut dapat dilihat pada stasiun 7 . Stasiun 7 memiliki konsentrasi logam Fe yang sangat tinggi sehingga membuat stasiun terdekat (St. 6 dan St. 8) memiliki konsentrasi logam Fe yang tinggi pula, sebaliknya, terlihat pada tiga stasiun terakhir. Nilai konsentrasi logam Fe pada ketiga stasiun tersebut masih berada dalam keadaan normal. Hal ini disebabkan karena ketiga stasiun tersebut berada jauh dan diapit beberapa stasiun sampel dengan konsentrasi yang rendah. 


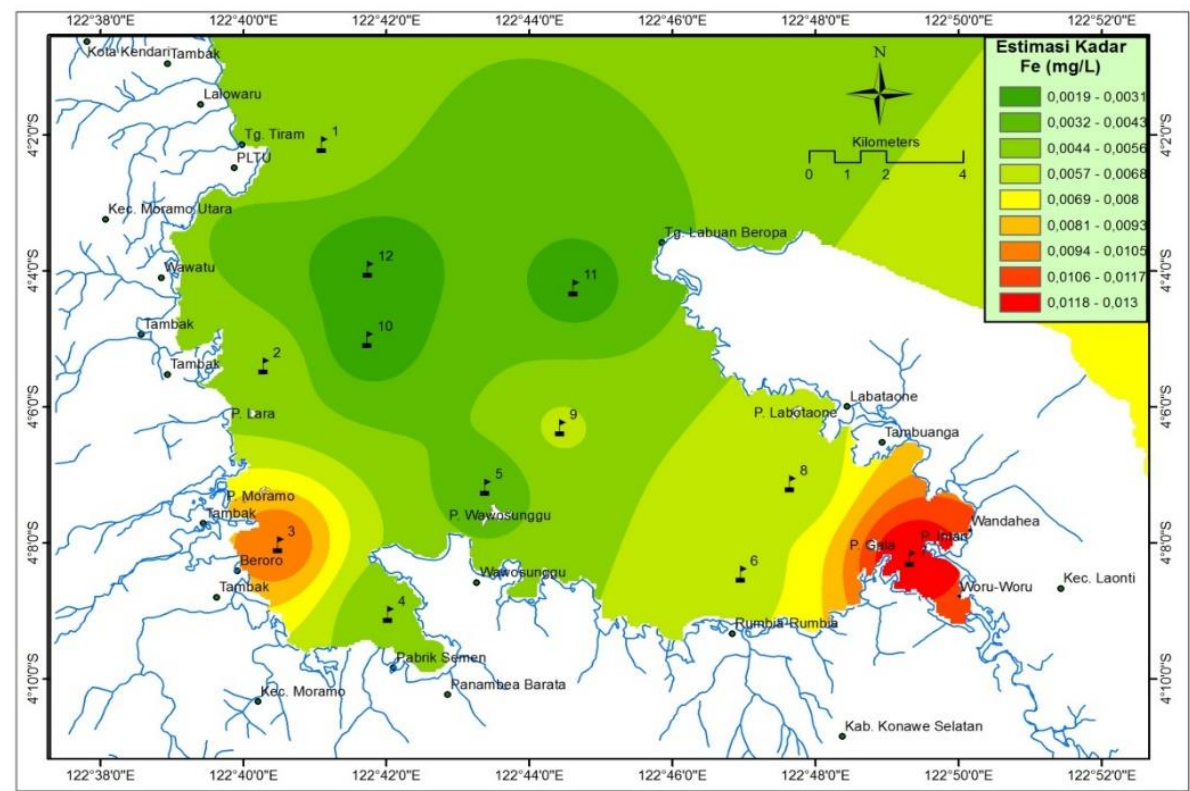

Gambar 4. Interpolasi IDW logam berat Fe di Perairan Teluk Staring.

Hasil analisis spasial menunjukkan di daerah pesisir Desa Woru-woru (dekat muara Sungai Laonti) hingga Pulau Gala dan Desa Wandahea hingga Pulau Intan telah terkontaminasi logam Fe dengan kisaran 0,0106-0,013 ppm. Hal yang sama telihat pada Desa Beroro yang juga telah terkontaminasi akibat adanya sungai sebagai sumber input logam Fe dengan kisaran 0,0094-0,0105 ppm. Berbeda halnya dengan desa-desa dan pulau lainnya di perairan Teluk Staring yang masih berada dalam kondisi tidak terkontaminasi dari cemaran logam Fe. Bagian barat-barat laut teluk (Pulau Lara-Desa Lalowaru), bagian selatan (pabrik semen, desa wawosunggu) hingga mulut teluk dan bagian timur (Desa Tambuanga) hingga pesisir Tanjung Labuan Beropa masih dalam status aman.

\subsection{Analisis Faktor Kontaminasi (Contamination Factor/ CF)}

Faktor kontaminasi merupakan salah satu indeks yang digunakan untuk menilai faktor kontaminasi untuk satu unsur logam berat. Faktor kontaminasi dapat menggambarkan tingkat kontaminasi logam berat tertentu pada suatu perairan. Hasil analisis faktor kontaminasi logam Fe dapat dilihat pada Tabel 2.

Tabel 2. Kategori Kontaminasi Logam Fe di 12 Stasiun Sampling

\begin{tabular}{ccc}
\hline Stasiun & CF $^{*}$ & CF $^{* *}$ \\
\hline$\# 1$ & 1,57 & 0,535 \\
$\# 2$ & 1,51 & 0,515 \\
$\# 3$ & 3,09 & 1,049 \\
$\# 4$ & 1,29 & 0,441 \\
$\# 5$ & 1,06 & 0,361 \\
$\# 6$ & 1,91 & 0,648 \\
$\# 7$ & 3,81 & 1,296 \\
$\# 8$ & 1,73 & 0,588 \\
$\# 9$ & 1,69 & 0,575 \\
$\# 10$ & 0,63 & 0,214 \\
$\# 11$ & 0,75 & 0,254 \\
$\# 12$ & 0,55 & 0,187 \\
\hline *Pembanding [16] ${ }^{* *}$ Pembanding [7] &
\end{tabular}

Berdasarkan hasil analisis yang disajikan pada Tabel 2, kontaminasi tinggi oleh logam Fe terlihat pada stasiun 3 dan 7. Sebaliknya, kontaminasi rendah terlihat pada 3 stasiun terakhir. Nilai CF yang diperoleh tersebut mengindikasikan bahwa, dekat atau jauhnya sumber masukan logam Fe mempengaruhi tingkat kontaminasi logam Fe. Hal serupa dinyatakan Werdianti [31] yang menyatakan nilai faktor kontaminasi logam berat $\mathrm{Cu}, \mathrm{Zn}$ dan Fe berbeda-beda dan pada salah satu 
stasiun penelitian memiliki nilai CF lebih rendah dibanding stasiun lainnya yang disebabkan karena sumber masukan logam berat pada stasiun tersebut lebih sedikit daripada stasiun lainnya dan letaknya yang cukup jauh dari sumber pencemar.

\subsection{Hubungan pH, Suhu dan Salinitas Air terhadap Kandungan Logam Fe}

Berdasarkan hasil penelitian diperoleh beberapa parameter lingkungan yang telah di ukur pada lokasi penelitian, sebagai faktor pendukung hadirnya logam berat terutama logam berat besi di kawasan perairan Teluk Staring, Sulawesi Tenggara. Nilai parameter lingkungan tersebut dan standar baku mutu logam Fe dapat dilihat di Tabel 1.

Suhu pada saat sampling masih berada pada kisaran standar baku mutu yang ditetapkan oleh Menteri Negara Lingkungan Hidup yaitu $28-31^{\circ} \mathrm{C}$ [32]. Sama halnya dengan $\mathrm{pH}$, dimana $\mathrm{pH}$ yang terukur juga masih berada pada kisaran baku mutu yang ditetapkan yakni 7-8,5 [32]. Dengan kata lain, suhu dan $\mathrm{pH}$ yang terukur masih dalam keadaan normal sehingga logam berat tetap sukar terurai dalam bentuk partikel ataupun padatan tersuspensinya.

Berbeda halnya dengan salinitas, nilai salinitas yang terukur pada 12 stasiun sampling berkisar antara $24,33-34,63 \%$ (rata-rata 33,86\%). Tabel 1 memperlihatkan nilai salinitas pada stasiun 5 masih sesuai standar baku mutu air laut menurut Menteri Negara Lingkungan Hidup [32] yakni berkisar antara 33-34\%, sedangkan stasiun lainnya yang mengalami kondisi moderat yang bervariasi dari standar baku mutu. Darmono [19] menyatakan bahwa pada perairan dengan salinitas yang tinggi dijumpai kandungan logam berat yang rendah di mana dalam kondisi dengan salinitas tinggi logam berat akan sukar terurai dalam bentuk partikel atau padatan tersuspensinya serta lambat laun akan mengalami pengendapan ke dasar perairan.

Menurut Rahman dan Mansyur [1], Teluk Staring merupakan suatu kawasan teluk semi terbuka yang berhadapan langsung dengan Laut Banda. Tingginya nilai salinitas pada ke empat stasiun terakhir yakni stasiun 9, 10, 11 dan 12 yang berada pada daerah teluk staring bagian dalam dengan nilai salinitas berturut-turut yaitu sebesar 36,$11 ; 36,32 ; 35,87$ dan $36,24 \%$, diduga disebabkan karena adanya suplai konsentrasi garam yang tinggi dari air laut di perairan Laut Banda yang berlangsung secara terus-menerus.

Gambar 1 memperlihatkan bahwa stasiun 7 yang berada di daerah aliran Sungai Laonti memiliki nilai salinitas terendah jauh di bawah standar baku mutu air laut yang ditetapkan oleh Menteri Negara Lingkungan Hidup [32] yaitu sebesar 24,83\%o. Di daerah muara, air laut dengan konsentrasi garam tinggi akan bercampur dengan air tawar dengan konsentrasi garam rendah dari air sungai dan terjadi proses pengadukan air sehingga terbentuk air payau dengan konsentrasi garam yang rendah. Hal ini sesuai dengan apa yang dikemukakan oleh Nontji [33] yang menyatakan bahwa salinitas suatu perairan cenderung berubah-ubah yang disebabkan oleh beberapa faktor salah satu yaitu masuknya air tawar.

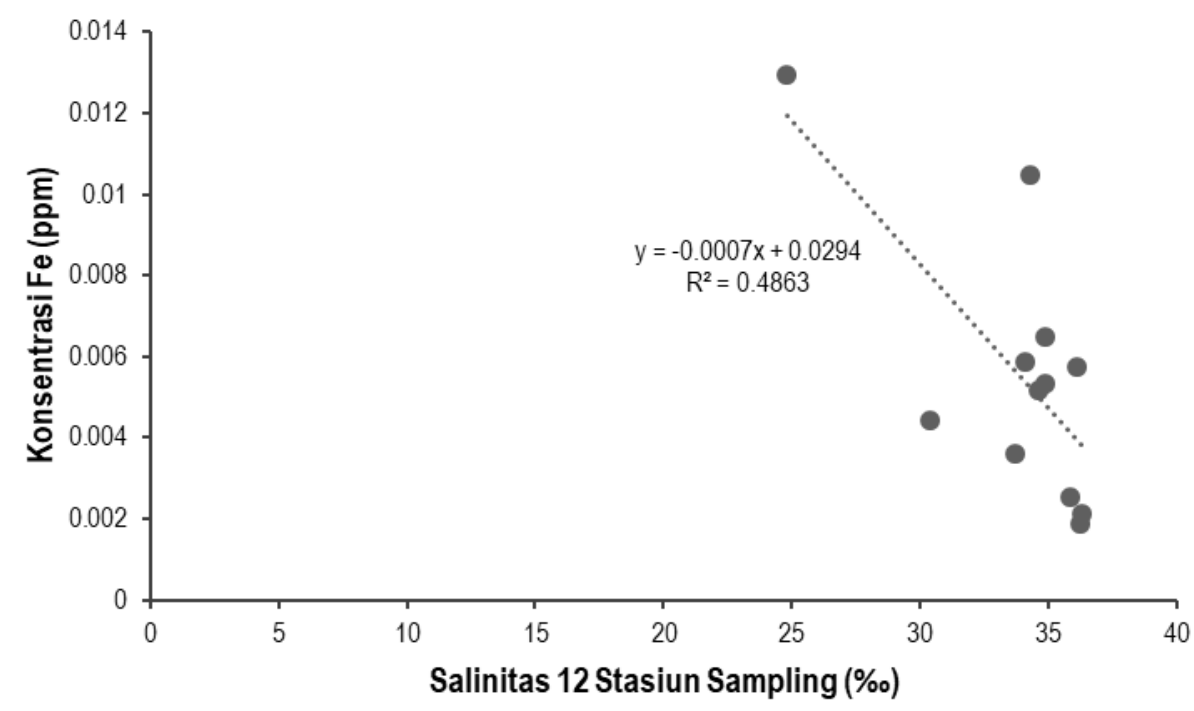

Gambar 5. Grafik hubungan salinitas air dengan kadar logam Fe.

Gambar 5 memperlihatkan bahwa salinitas memiliki nilai koefisien korelasi yaitu 0,4863 yang lebih signifikan dibandingkan dengan parameter lainnya. Penting untuk dicatat bahwa pengambilan sampel pada penelitian ini hanya dilakukan 1 kali (tanpa ulangan). Armid [28] menyatakan bahwa untuk sampai pada kesimpulan yang valid dengan tingkat presisi yang baik mengenai pengaruh suatu parameter lingkungan air terhadap kandungan logam tertentu, diperlukan lokasi pengambilan sampel yang lebih banyak dengan frekuensi ulangan sampling yang cukup $(n \geq 3)$. 


\section{Kesimpulan}

Kadar logam Fe di 12 stasiun penelitian yang terukur berkisar antara 0,00187-0,01296 ppm. Kadar logam tertinggi terdapat pada daerah muara Sungai Laonti. Distribusi spasial logam Fe menampilkan 9 kelas (value) dimana kontur yang sama memberikan nilai yang berada pada kisaran tertentu. Nilai faktor kontaminasi logam Fe di perairan Teluk Staring bersifat moderat. Kontaminasi tertinggi oleh logam Fe terdapat pada stasiun 7. Salinitas perairan memiliki relasi yang lebih tinggi dibanding variabel lingkungan perairan lainnya dengan koefisien korelasi sebesar 0,4863.

\section{Ucapan Terima Kasih}

Penulis mengucapkan terima kasih kepada kemristekdikti yang telah memberikan dana hibah penelitian. Banyakbanyak terimakasih juga kami ucapkan kepada Ketua Jurusan Kimia FMIPA Universitas Halu Oleo dan dosen pembimbing kami yang selalu meluangkan waktu dan dukungannya kepada kami dalam melakukan seluruh kegiatan ini. Semoga apa yang lakukan dalam kegiatan ini dapat bermanfaat bagi semua pihak.

\section{Daftar Pustaka}

[1] A. Rahman \& A. Mansyur, "Kesesuaian Pemanfaatan Perairan bagi Pengembangan Perikanan Budidaya di Kawasan Teluk Staring Konawe Selatan," Jurnal Bisnis Perikanan, vol. 3, no. 1, pp. 31-48, 2016.

[2] Nalarati, L. O. L. Ola, \& R. D. Siang, "Analisis Nilai Tukar Nelayan Rumput Laut di Desa Ranooha Raya Kecamatan Moramo Kabupaten Konawe Selatan," Jurnal Sosial Ekonomi Perikanan, vol. 1, no. 1, pp. 1-9, 2016.

[3] A. Rajab, Bahtiar, \& Salwiyah, "Studi Kepadatan dan Distribusi Kerang Lahubado (Glauconome sp) di Perairan Teluk Staring Desa Ranooha Raya Kabupaten Konawe Selatan," Jurnal Manajemen Sumber Daya Perairan, vol. 1, no. 2, pp. 103-114, 2016.

[4] Y. Hala, P. Taba, \& M. Mariani, "Fitosorpsi Bi-logam $\mathrm{Cd}(\mathrm{II})$ dan $\mathrm{Cu}(\mathrm{II})$ oleh Chaetoceros calcitrans dalam Medium Conwy," Marina Chimica Acta, vol. 11, no. 1, pp. 30-35, 2010.

[5] T. Wijayanti, "Profil Pencemaran Logam Berat pada Perairan Daerah Aliran Sungai (DAS) Grindulu Pacitan," Jurnal IImiah Sains, vol. 17, no. 1, pp. 19-25, 2017.

[6] Boybul \& I. Haryati, "Analisis Unsur-Unsur dalam Sedimen Laut menggunakan Spektrometer Gamma," Urania: Jurnal IImiah Daur Bahan Bakar Nuklir, vol. 13, no. 4, pp. 66-73, 2007.

[7] Hendrawati, "Analisis Beberapa Parameter Kimia dan Kandungan Logam pada Sumber Air Tanah di Sekitar Pemukiman Mahasiswa UIN Syarif Hidayatullah Jakarta," Jurnal Valensi, vol. 1, no. 1, pp. 14-18, 2007.

[8] M. R. Hasan, M. Z. H. Khan, M. Khan, S. Aktar, M. Rahman, F. Hossain, \& A. S. M. M. Hasan, "Heavy Metals Distribution and Contamination in Surface Water of the Bay of Bengal Coast," Cogent Environmental Science, vol. 2, 2016.

[9] S. Srichandan, R. C. Panigrahy, S. K. Baliarsingh, S. Rao B., P. Pati, B. K. Sahu, \& K. C. Sahu, "Distribution of Trace Metals in Surface Seawater and Zooplankton of the Bay of Bengal, Off Rushikulya Estuary, East Coast of India," Marine Pollution Bulletin, vol. 111, no. 1-2, pp. 468-475, 2016.

[10] J. Zhang, F. Zhou, C. Chen, X. Sun, Y. Shi, H. Zhao, \& F. Chen, "Spatial Distribution and Correlation Characteristics of Heavy Metals in the Seawater, Suspended particulate Matter and Sediments in Zhanjiang Bay, China," PLoS ONE, vol. 13, no. 8, 2018.

[11] A. J. Reichelt-Brushett \& G. McOrist, "Trace Metals in the Living and Nonliving Components of Scleractinian Corals," Marine Pollution Bulletin, vol. 46, no. 12, pp. 1573-1582, 2003.

[12] I. D. Sukaryono \& P. D. Riardi, "Pemantauan Kandungan Logam Berat Pd dan Cd pada Sedimen di Pesisir Teluk Ambon Dalam Sebagai Indikasi Tingkat Pencemaran," Majalah BIAM, vol. 14, no. 1, pp.1-7, 2018.

[13] Fiskanita, B. Hamzah, \& Supriadi, "Analisis Logam Timbal $(\mathrm{Pb})$ dan Besi (Fe) dalam Air Laut di Pelabuhan Desa Paranggi Kecamatan Ampibabo," Jurnal Akademika Kimia, vol. 4, no. 4, pp. 175-180, 2015.

[14] K. A. Anderson, Analytical Techniques for Inorganic Contaminants. Gaitherburg, MD: AOAC International, 1999.

[15] R. E. Walpole, Pengantar Statistika, Edisi ke-3. Jakarta: Gramedia, 1995.

[16] K. K. Turekian, Oceans. Foundations of Earth Science Series. Englewood: Prentice-Hall, 1968.

[17] H. Effendi, Telaah Kualitas Air. Yogyakarta: Kanasius, 2003.

[18] W. Komarawidjaya, "Paparan Limbah Cair Industri mengandung Logam Berat pada Lahan Sawah di Desa Jelegong, Kecamatan Rancaekek, Kabupaten Bandung," Jurnal Teknologi Lingkungan, vol. 18, no. 2, pp.173-181, 2017.

[19] Darmono, Lingkungan Hidup dan Pencemaran: Hubungannya dengan Toksikologi Senyawa Logam. Jakarta: Universitas Indonesia Press, 2001.

[20] B. Hamuna, R. H. R. Tanjung, Suwito, H. K. Maury, \& Alianto, "Kajian Kualitas Air Laut dan Indeks Pencemaran Berdasarkan Parameter Fisika-Kimia di Perairan Distrik Depapre, Jayapura," Jurnal IImu Lingkungan, vol. 16, no. 1 , pp. 35-43, 2018. 
[21] T. A. Hutagalung, "Penentuan Kadar Besi ( $\mathrm{Fe})$, Timbal $(\mathrm{Pb})$ dan Seng $(\mathrm{Zn})$ pada Air Sumur di Kawasan Binjai Utara dengan Metode Spektrofotometer Serapan Atom (SSA) di Laboratorium Kesehatan Daerah," Laporan Tugas Akhir, Universitas Sumatra Utara, Medan, 2018.

[22] K. Batara, B. Zaman, \& W. Oktiawan, "Pengaruh Debit Udara dan Waktu Aerasi terhadap Efisiensi Penurunan Besi dan Mangan menggunakan Diffuser Aerator pada Air Tanah," Jurnal Teknik Lingkungan, vol. 6, no. 1, pp. 1-10, 2017.

[23] K. F. A. Kamarati, I. A. Marlon, \& M. Sumaryono, "Kandungan Logam Berat Besi (Fe), Timbal (Pb) dan Mangan (Mn) pada Air Sungai Santan," Jurnal Penelitian Ekosistem Dipterokarpa, vol. 4, no. 1, pp. 49-56, 2018.

[24] U. H. Hasyim, "Review: Kajian Adsorpsi Logam dalam Pelumas Bekas dan Prospek Pemanfaatannya Sebagai Bahan Bakar," KONVERSI, vol. 5, no. 1, pp. 11-16, 2016.

[25] M. Kasman, Suhendra, P. Herawati, Salmariza, Hariyanto, \& F. Yanti, "Imobilisasi Polutan Fe dan Pb dalam Limbah Oli Bekas dengan Solidifikasi/Stabilisasi," Jurnal Litbang Industri, vol. 6, no. 2, pp. 127-134. 2016.

[26] M. H. Dahlan, A. Setiawan, \& A. Rosyada, "Pemisahan Oli Bekas dengan menggunakan Kolom Filtrasi dan Membran Keramik Berbahan Baku Zeolit dan Lempung," Jurnal Teknik Kimia, vol .1, no. 20, pp. 38-45, 2014.

[27] D. Widiyanto, "Pemanfatan Limbah Oli Bekas sebagai Bahan Bakar Pembantu Peledakan (Anfo) pada Kegiatan Pertambangan Batubara (Kasus Pemanfaatan Limbah Oli Bekas di PT. JMB Group)," dalam Prosiding Seminar Nasional Teknologi Pengelolaan Limbah XIV, 2016, pp. 52-59.

[28] Armid, "Distribusi Spasial Logam Berat Pb pada Perairan Teluk Kendari, Sulawesi Tenggara," Biowallacea: Jurnal Penelitian, vol. 2, no. 2, pp. 220-228, 2015.

[29] M. Saffari, J. Yasrebi, H. Fathi, N. Karimian, M. Moazallahi, \& R. Gazni, "Evaluation and Comparison of Ordinary Kriging and Inverse Distance Weighting Methods for Prediction of Spatial Variability of Some Soil Chemical Parameters," Research Journal of Biological Science, vol. 4, no. 1, pp. 93-102, 2009.

[30] H. Purnomo, "Aplikasi Metode Interpolasi Inverse Distance Weighting dalam Penaksiran Sumberdaya Laterit Nikel (Studi Kasus di Blok R, Kabupaten Konawe-Sulawesi Tenggara)," Jurnal IImiah Bidang Teknologi ANGKASA, vol. 10, no. 1, pp.49-60, 2018.

[31] T. Werdianti, "Analisis Tingkat Pencemaran Logam Berat ( $\mathrm{Cu}, \mathrm{Zn}$, dan Fe) pada Sedimen Permukaan di Perairan Kawasan Industri Gresik (KIG) Kabupaten Gresik, Jawa Timur," Skripsi, Universitas Brawijaya, Malang, 2018.

[32] Menteri Negara Lingkungan Hidup, Keputusan Menteri Negara Lingkungan Hidup Nomor 51 Tahun 2004 tentang Baku Mutu Air Laut. Jakarta: Menteri Negara Lingkungan Hidup, 2004.

[33] A. Nontji, Laut Nusantara. Jakarta: Djambatan, 2005. 